\title{
Tribological Behavoiur of Silicon Carbide/ Rice Husk ash Reinforced Al7075 Hybrid Composites Using Optimization Techniques
}

Sivasakthivel P S ( $\sim$ sivasakthivel@mech.sastra.edu )

Shanmugha Arts Science Technology and Research Academy School of Mechanical Engineering https://orcid.org/0000-0002-3634-2331

R. Sudhakaran

SNS College of Engineering

\section{Research Article}

Keywords: Composites, SiC, rice husk ash, wear, microstructure, hardness, ANOVA

Posted Date: June 21st, 2021

DOl: https://doi.org/10.21203/rs.3.rs-621659/v1

License: (c) (i) This work is licensed under a Creative Commons Attribution 4.0 International License.

Read Full License 
Tribological behavoiur of silicon carbide/ rice husk ash reinforced $\mathbf{A 1 7 0 7 5}$ hybrid composites using optimization techniques

\title{
P.S. Sivasakthivel ${ }^{1 *}$, R. Sudhakaran ${ }^{2}$
}

${ }^{1}$ P.S. Sivasakthivel*

School of Mechanical Engineering

SASTRA University,

Tirumalaisamudram,

Thanjavur - 613401, Tamil Nadu, India.

E-mail - sivasakthivel@mech.sastra.edu

ORCID: 0000-0002-3634-2331

* Corresponding author

${ }^{2}$ R. Sudhakaran

Department of Mechanical Engineering, SNS College of Engineering,

Coimbatore - 641107

Tamil Nadu, India.

Phone: 0422 - 6465201, 6465202

Fax no: 0422 - 2666258, 2669091

E-mail: - absudha@yahoo.co.in

\begin{abstract}
In this paper, aluminium alloy A17075 was reinforced with silicon carbide (SiC) particles and rice husk ash to improve hardness and wear resistance. The SiC particulate and rice husk ash composition in composite were taken in five different proportions such as $3 \%, 6 \%, 9 \%, 12 \%$ and $15 \%$ for $\%$ of $\mathrm{SiC}$ particulates and $2 \%, 4 \%, 6 \%, 8 \%$ and $10 \%$ for $\%$ of rice husk ash. Nine different compositions to cater the above proportions were fabricated using stir casting technique. Microstructure examination was conducted on the prepared specimen using optical microscope to determine the homogeneity of reinforced particle distribution. The tribological
\end{abstract}


properties were examined by measuring the wear on the prepared specimen using pin on disc apparatus. The input parameters considered were materials factor such as $\%$ of $\mathrm{SiC}$ and $\%$ of rice husk ash and mechanical wear factors such as load applied, speed of rotation and sliding distance. The design of experiment technique, central composite design (CCD) was employed for conducting experiments with different combination of parameters. Empirical relationship was devised to predict wear of the composite specimen in terms of parameters such as $\% \mathrm{SiC}, \%$ of rice husk ash, load applied, speed of rotation and sliding distance. The empirical relations adequacy was tested using Analysis of variance (ANOVA). The direct and interaction effect of input parameters on wear were analyzed which helps to determine the significance of these parameters. Microstructure examinations were conducted to analyze assimilation and uniform distribution of reinforcement particles in prepared composites. Optimization of process parameter was obtained for minimum wear using genetic algorithm.

Keywords: Composites, $\mathrm{SiC}$, rice husk ash, wear, microstructure, hardness, ANOVA

\section{Introduction}

Metal matrix composites, MMCs are compounded with at least two constituent parts. One part is a metal and other part constitute of other metal/ ceramic/ organic materials. If in such combinations two or more materials reinforces with the matrix metals, then the composites are known as hybrid composite. MMCs are fabricated to have enhanced mechanical properties such as good wear and corrosive resistance, high strength, low density, good thermal conductivity, low coefficient of expansion, etc. Owing to its unique characteristics and properties, MMCs find wide application in automobile parts, aerospace structures, deck panels, etc. Particulate reinforced MMCs contain reinforcement materials as either particles or platelets that range in size from 0.5 to $100 \mu \mathrm{m}$. The MMCs are fabricated by the accretion of reinforcement material in the matrix metal. Some suitable methods for the fabrication of MMCs are stir casting [1,2,3], squeeze casting [4], spray atomization and co-deposition [5], plasma spraying [6] and powder metallurgy technique [7]. The need for hybrid MMCs had been increasing in the recent years for the various product developments with high stiffness and strength. The most common matrix material used was aluminium and its alloy due to its commercial standpoint which is employed for structural application in aerospace, automotive and sports equipment sectors. The 
reinforcement materials are implanted into a matrix metal material to enhance its mechanical properties such as wear resistance and hardness. Non oxide ceramic material SiC exhibits good thermal conductivity and low density is commonly used reinforcement material. Rice husk ash is an agricultural by product available in abundance contains amorphous silica and carbon used as reinforcement materials. Sliding wear is perceived as a relative motion between two surfaces in contact under load which is inevitable in many industrial applications. The composite materials fabricated should be highly wear resistant. Aluminium MMCs manufactured with reinforcement of both $\mathrm{SiC}$ particulates and rice husk ash resulted in enhanced wear resistance compared to the reinforcement with either $\mathrm{SiC}$ alone. In this study the MMCs fabricated is of particulate type, where Al 7075 matrix composite was reinforced with different percentage of SiC particulate and rice husk ash using stir casting technique. Further the analysis was conducted to understand the effect of independent parameters on the wear resistance of the composites fabricated.

Different researchers have been carried out investigations on the mechanical properties of hybrid composites and shows an enhancement. The inclusions of mica and SiC particles reinforcement and its positive effects was reported by [8]. It has been concluded that increase in mica and SiC mass fraction resulted in better strength, wear resistance and hardness. Wear mechanism based on the pattern and stability of oxide layer was described by [9] in aluminum composites impregnated with SiC particles. Baradeswaran et al [10] fabricated MMCs with aluminium alloy (Al 7075) as matrix materials and reinforcement with various proportions of boron carbide. It was concluded that the wear resistance improves with the increasing content of boron carbide particles. The reinforcement of $\%$ of particulate boron carbide and rice husk in aluminium alloy were investigated by [11]. It was concluded that the hardness and strength increases with an increase in $\%$ of reinforcement. The effect of heat treatment in $\mathrm{Al}$ alloy reinforce with $6 \%$ rice ash husk was described by [12]. Three different aging processes is employed at temperature $135^{\circ} \mathrm{C}, 175^{\circ} \mathrm{C}$ and $225^{\circ} \mathrm{C}$. Improvement in hardness and reduction in wear was observed at aging temperature $175^{\circ} \mathrm{C}$ in composite development. More importance are given for hybrid composites by adding two different reinforcements in matrix alloy resulted in better tribological characteristics. Tribological properties of hybrid composites with $\mathrm{Al}$ as matrix alloy and $\mathrm{SiC}$ and graphite as reinforcement as particulate of were investigated by $[13,14]$. Results have shown that the $\mathrm{SiC}$ and graphite particles positively influences the tribological behavoiur of fabricated composites. Friction and wear behavoiur of hybrid composites composed of magnesium 
reinforced with $\mathrm{SiC}$ and grapheme oxide using solvent based powder metallurgy method was studied by [15]. Predictive model was developed and optimal combination of process parameter for specific wear rate was obtained. Tribological studies on wear measurement of alumina reinforced MMCs was conducted by [16] for varying load conditions and sliding speed. It was concluded that wear rate increases with an increase in load. Wear characteristics of $\mathrm{A} 356 / \mathrm{SiC}_{\mathrm{MoS}}$ [17], Al6061/SiC/Al ${ }_{2} \mathrm{O}_{3}$ [18], Al6061/SiC/B 4 C/talc [19], AA1100/SiC/B 4 C [20], and A17075/SiC/graphite [21] hybrid composite fabricated using friction stir processing were analyzed and found an improvement in wear resistance. Ravindran et al [22] studied the tribological properties of $\mathrm{Al} / \mathrm{SiC} /$ graphite hybrid $\mathrm{MMCs}$ using powder metallurgy technique. They concluded that the addition of both a hard reinforcement (e.g., SiC) and soft reinforcement (e.g., graphite) significantly improved the wear resistance of hybrid MMCs. Thus hybrid MMCs consist of matrix metal alloy with strongly reinforced multiple particulates enhance the wear resistance properties. Dey et al [23] studied the inclusion of SiC particulates in A12024 alloy and investigated the effect of SiC content on mechanical properties and tribological behaviour of the prepared composites.

The design of experiment techniques intends in describing information on variation collected under certain conditions that are assumed to impersonate the variation. Central composite response surface methodology was employed by [24] to study the direct and interaction effect of volume fraction, matrix particle size and reinforcement particle size on the wear resistance of $\mathrm{Al} / \mathrm{SiC}_{\mathrm{p}}$ composite. Taguchi technique was used by [25] for optimization of controlling parameters such as sliding distance and applied in wear test of $\mathrm{Al} / \mathrm{Al}_{2} \mathrm{O}_{3}$ composites. Poria et al. [26] studied wear behavior of Al-TiB2 composites using Taguchi based L27 orthogonal array design matrix. Wear and friction behaviour of pure aluminium, Al alloy (Al-112Si) reinforced with $\mathrm{ZrC}$ with various percentage combinations was studied by [27] using full factorial experimental design.

The optimization of composite materials for enhanced properties and its utility to determine best combination parameters has been subjected to exhaustive research. Chidozie and Chizoba [28] applied Non Dominated Sorting Genetic Algorithm II for multi objective optimization of Al 6351/ Egg Shell Reinforced composite. Chidozie et al [29] used genetic algorithm with artificial neural network as fitness function for multi objective optimization of A356 alloy/ cow horn 
particulate composite. . Sudarsana et al [30] employed genetic algorithm based neural network model to determine computationally fast and efficient analysis of interface strength of ceramic matrix composites. Gangadhara et al [31] used genetic algorithm to obtain optimal values of the input process parameters related to the powder metallurgy-based process of producing $\mathrm{Al} / \mathrm{SiC}$ composites.

The literature review revels that $\mathrm{SiC}$, graphite, $\mathrm{B}_{4} \mathrm{C}, \mathrm{TiO}_{2}, \mathrm{ZrC}$ and rice husk ash can be adequately mix up with aluminium alloy to form a hybrid MMCs. The low density and high thermal conductivity nature of $\mathrm{SiC}$ and heat resistant capability of rice husk ash makes the fabricated hybrid MMCs to exhibit superior mechanical properties. In this work, \% reinforcement of $\mathrm{SiC}$ and rice husk ash particles varied individually and independently which has not been considered in the previous work. The main objective of the present research is to establish empirical regression relations in terms of parameters such as \% SiC, \% rice husk ash, speed of rotation of disc, load and sliding distance to predict wear in the fabricated hybrid composite specimen. The direct and interaction effects of these parameters on wear, to understand the effect of these parameters on wear resistance were studied. The optimal values of considered process parameter on wear was determined using genetic algorithm (GA).

\section{Experimental set up}

\subsection{Stir casting technique}

Stir casting technique is an appropriate economical processing method to manufacture Al based MMCs. The experimental setup consist of furnace, reinforcement feeder, stirrer and a permanent mold. A pit type furnace is used to melt the metal and the temperature is measured using $\mathrm{J}$ type thermocouple. A reinforcement feeder attached along with furnace, through which the reinforcement particles and wetting agent particles poured in to the melt. A mechanical stirrer is used to form a vortex in the melt to mix the reinforcement particles and also to stir the melt to reduce oxidation. The stirrer is composed of stirrer rod, impeller blade, a variable speed motor and a regulator to govern the speed of motor. A mold is used for pouring mixed slurry and composites ingots are casted. The procedure for stir casting process are as follows. Before starting the process of melting in the furnace, it is preheated to $100^{\circ} \mathrm{C}$. The matrix materials was 
placed inside a graphite crucible and then the crucible is placed inside the furnace for melting. The temperature of the furnace was increased slowly in a time period of 2- $3 \mathrm{hrs}$. and maintained at that temperature for about 2 hrs. Once melting of matrix material is completed, the mechanical stirrer begins to stir to form a vortex in the molten metal to avoid oxidation and to facilitate reinforcement particles to add upon. Meanwhile the reinforcement particles are preheated in a different furnace. The preheated reinforcement particles are poured into the molten metal in the crucibles through feeder and the stirring process continuous. The stirring disperse the reinforcement particles in the matrix molten melt and maintain them in suspension. The melt slurry was thoroughly stirred to ensure uniform of mixture of dispersed reinforcement particles. The resulting mixture was cast into a steel mould of $20 \mathrm{~mm}$ diameter and final MMCs cast ingots is fabricated.

\subsection{MMCs fabrication}

Aluminium alloy A17075 was used as a matrix materials and powder particles $\mathrm{SiC}$ and rice husk ash were included as reinforcement materials. Al 7075 possess excellent castability, light weight, good oxidation resistance, better mechanical properties, etc., and used in the fabrication of structural elements in automotive and aerospace applications. $\mathrm{SiC}$ also called as carborundum was chosen as one of the reinforcement material owing to the fact as one of the most widely used particle material for aluminium alloy based MMCs. Since SiC is a ceramic materials, its inclusion in $\mathrm{Al}$ alloys increase hardness and wear resistance. Rice husk ash, a form of carbon is another material, which was chosen for reinforcement. It is easily available, a light weight material, economically lesser cost materials which is obtained from agricultural residue, can be used for effective reinforcement. Rice hush ash chemical composition varies with crop year and geographical regions, but predominately chemical proportions consist of $\mathrm{SiO}_{2}$ and $\mathrm{Al}_{2} \mathrm{O}_{3}$. Reinforcing rice husk ash enhances wear resistance and hardness of the MMCs.

The fabrication of hybrid MMCs is done using stir casting method, in which a molten aluminium matrix metal is mixed with a powder of dispersed of reinforcement particle, followed by casting and solidifying to a solid state. The matrix metal selected was Al 7075, which was received in the form of $2 \mathrm{~kg}$ ingot cylindrical rod. The chemical composition of $\mathrm{Al}$ 7075 is given in the table 1. 
Table 1. Chemical composition of Al7075

\begin{tabular}{cccccccccc}
\hline Material & $\mathbf{F e}$ & $\mathbf{C u}$ & $\mathbf{M n}$ & $\mathbf{M g}$ & $\mathbf{Z n}$ & $\mathbf{T i}$ & $\mathbf{C r}$ & $\mathbf{S i}$ & $\mathbf{A l}$ \\
\hline Percentage & 0.21 & 1.5 & 0.07 & 2.4 & 5.7 & 0.05 & 0.19 & 0.11 & 89.77 \\
\hline
\end{tabular}

The received A17075 ingots were cut into smaller pieces using bandsaw cutting machine of about 50 to 100 grams. The smaller size will facilitate the metal to melt faster in the furnace. The ingots after cutting into smaller pieces were washed with water and then dried. Metals of suitable amount, about 200 to 220 grams is placed into a graphite cylindrical crucible for each one experiments. The amount of $\mathrm{SiC}$ particles of size $20 \mu \mathrm{m}$ was varied as $3 \%, 6 \%, 9 \%, 12 \%$ and $15 \%$ relative to the volume of Al7075, each based on the combination given in the experimental design matrix. Dry rice husk was bought and it is burned in the furnace to make powdered ash. The amount of rice husk ash was varied as $2 \%, 4 \%, 6 \%, 8 \%$ and $10 \%$ relative to the volume of Al7075, each based on the combination given in the experimental design matrix. The silicon carbide particle due to high density remains at the bottom and rice husk ash due to is low density tend to float on the top of the molten metal, even at high stirring speed. This is due to poor wettability of these two substance with $\mathrm{Al}$ molten metal. To improve the wettability, about $1 \%$ of $\mathrm{Mg}$ particles are added as a wetting agent. $\mathrm{Al} 7075$ ingots, SiC particles, rice husk ash and $\mathrm{Mg}$ particles are weighted using a digital weighing machine with an accuracy of 0.01 grams. Pit type electrical furnace was employed for conducting experiments. The furnace was preheated initially before to start to melt. Al7075 collected in graphite crucible are kept steel chamber inside the furnace for melting. The temperature is then increased slowly to $850^{\circ}$ and maintained at that temperature. The reinforcement particles to be dispersed in the melt is preheated and added to the melt through feeder. The mechanical stirrer begins to stir to form a vortex in the molten metal. The stirring disperse the reinforcement particles in the matrix molten melt and maintain them in suspension. The melt slurry was thoroughly stirred to ensure uniform of mixture of dispersed reinforcement particles. The resulting mixture was cast into a steel mould of $20 \mathrm{~mm}$ diameter and final MMCs cast ingots is fabricated. The synthesized MMCs specimens are of the following combinations \% of reinforcement of SiC and rice husk ash as given in the table 2 and shown in the figure 1. 
Table 2 Percentage composition of aluminium metal matrix composites

\begin{tabular}{ccccc}
\hline Sample No. & \% SiC & \% Rice Husk Ash & \% Al 7075 & \% Mg \\
\hline 1 & 6 & 4 & 89 & 1 \\
2 & 12 & 4 & 83 & 1 \\
3 & 12 & 8 & 79 & 1 \\
4 & 6 & 8 & 85 & 1 \\
5 & 3 & 6 & 90 & 1 \\
6 & 15 & 6 & 78 & 1 \\
7 & 9 & 2 & 88 & 1 \\
8 & 9 & 10 & 80 & 1 \\
9 & 9 & 6 & 84 & 1 \\
\hline
\end{tabular}

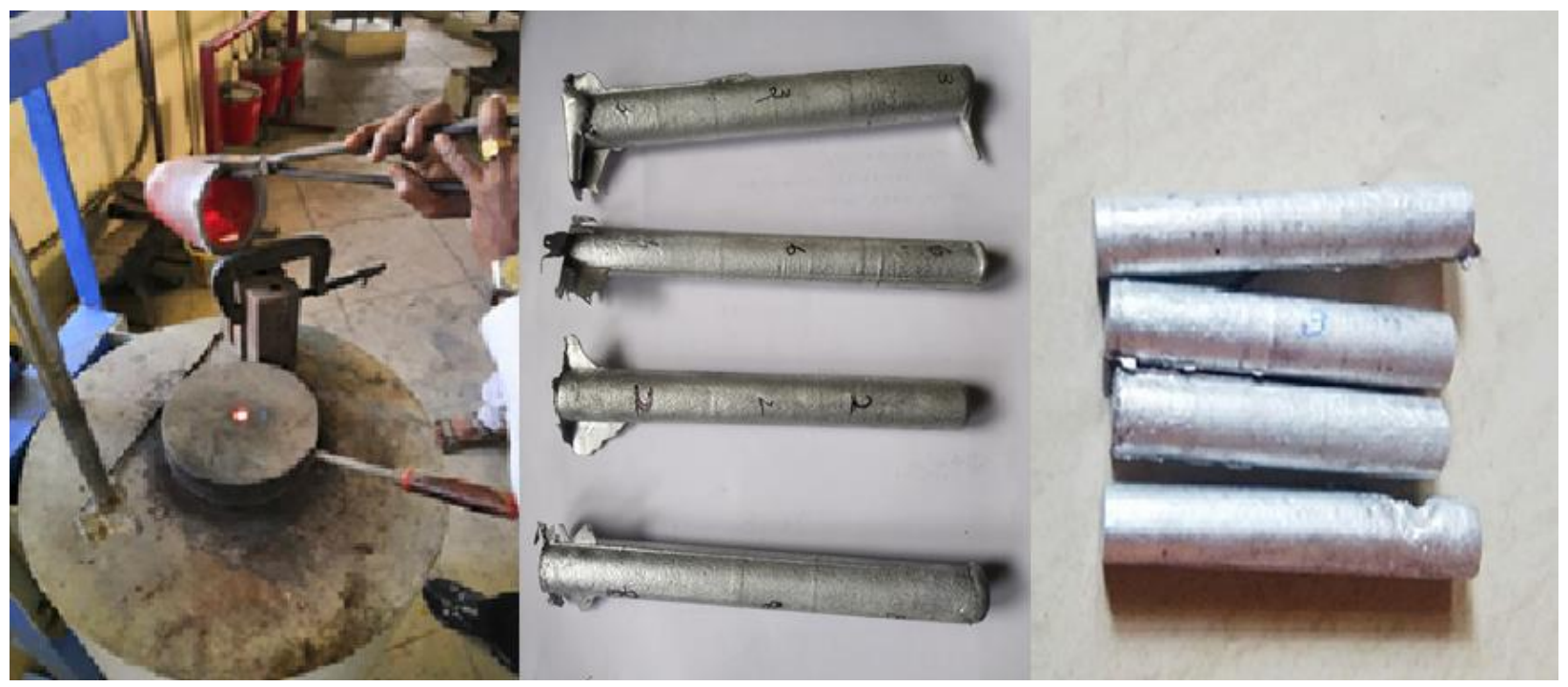

Figure 1. Stir casting process and fabricated MMCs

\subsection{Experimental design}

$1 / 2$ replicate central composite rotatable experimental designs were employed for conducting the experiment [32]. This experimental design is one of the methods of response surface methodology design of experiments technique. It is a mathematical and statistical approach employed for developing predictive statistical equations for the response measure of the process and to study the influence of process variable within its range [33]. When the input independent 
process parameter were controllable variable, then response of the process can be represented in terms of process parameters as given in the equation (1) as

$$
\text { Response, } \mathrm{y}_{\mathrm{j}}=\psi\left(\mathrm{x}_{1 \mathrm{j}}, \mathrm{x}_{2 \mathrm{j}}, \ldots \ldots, \mathrm{x}_{3 \mathrm{j}}\right)+\mathrm{e}_{\mathrm{j}}
$$

Where $\mathrm{j}=1,2, \ldots \ldots, \mathrm{N}$ represents the $\mathrm{N}$ observation in the factorial experiment, $\mathrm{x}_{\mathrm{ij}}=$ the level of the $\mathrm{i}^{\text {th }}$ factor in the $\mathrm{j}^{\text {th }}$ observation and $\mathrm{e}_{\mathrm{j}}=$ residual measures error of the $\mathrm{j}^{\text {th }}$ observation. The function $\psi$ is called the response surface. The mathematical formulation of response $\psi$ was approximated within the experimental region using polynomials in terms of process variables. The benefit of using polynomial response surface is easy to fit. The appropriate choice of design, a quadratic polynomial function in 5 variables which contains 21 coefficients is not an intricate task. The formulated polynomial surface has to be considered as an approximation. A polynomial surface should be considered as an estimation of function $\psi$ within the range of input process parameters. The formulated quadratic polynomials which represent the relationship between the response and input parameter is (2) given below [34]

$$
\mathrm{y}_{\mathrm{u}}=\mathrm{b}_{0}+\sum_{i=1}^{k} \mathrm{~b}_{\mathrm{i}} \mathrm{x}_{\mathrm{iu}}+\sum_{i=1}^{k} \mathrm{~b}_{\mathrm{ii}} \mathrm{x}_{\mathrm{iu}}^{2}+\sum_{i<j=1}^{k} b_{i j} x_{i \mathrm{u}} x_{j u}
$$

The above equation contains a linear terms in $\mathrm{x}_{\mathrm{iu}}$, a quadratic terms in $\mathrm{x}_{\mathrm{iu}}{ }^{2}$ and an interactive terms $\mathrm{x}_{\mathrm{iu}} \mathrm{x}_{\mathrm{ju}}$. $\mathrm{b}_{0}$ represents constant terms, $\mathrm{b}_{\mathrm{i}}, \mathrm{b}_{\mathrm{ii}}$ and $\mathrm{b}_{\mathrm{ij}}$ represents the coefficients of the above equations for constant, linear terms, quadratic (squared) terms and cross product (interactive) terms. The computation of the constant and coefficient can be made easier based on the criterion of rotatability. According to the criterion of rotatability, the standard error of the response ' $y_{u}$ ' at any point on the fitted surface can be computed from the results of the experiment. Evaluated standard error will be in terms of the coordinate's $\mathrm{x}_{\mathrm{iu}}$ of the point. The standard errors are equal and are at same distance $\rho$ from the center of the region for all the points. ie., [35]

$$
\mathrm{x}_{1 \mathrm{u}}{ }^{2}+\mathrm{x}_{2 \mathrm{u}}{ }^{2}+\ldots \ldots+\mathrm{x}_{\mathrm{ku}}{ }^{2}=\rho^{2}=\text { constant }
$$

The rotatable design is obtained by conducting experiments at number of points equally spaced around the circumference of a sphere with center as origin, plus experiments in the replicated center points. The central composite rotatable design is a $2^{\mathrm{k}}$ factorial design with added $2 \mathrm{~K}$ star points and replicated central points. The star points are considered with one parameter at lower or higher limits, while the other parameters are set at the middle level. The center points are 
replicated to provide degrees of freedom to compute experimental error and to determine the precision of the responses. The total number of experiment combinations is $\left(2^{\mathrm{k}}\right.$ factorial points + $2 \mathrm{~K}$ star points + replicated center points). Rotatable design for any number $\mathrm{k}$ of $\mathrm{x}$-variable can be formed from these three components. The value of $\beta$ (the distance of centre point to circumference of spherical space) must be $2^{\mathrm{k} / 4}$ for full replicate and $2^{(\mathrm{k}-1) / 4}$ for $1 / 2$ replicate [36].

In this study, the tribological properties were examined by measuring the wear on the prepared specimen using pin on disc apparatus. The input parameters such as $\%$ of $\mathrm{SiC}, \%$ of rice husk ash, load applied, speed of rotation and sliding distance were considered as process parameters (shown in the table 3), the wear of prepared MMCs measured using wear tester was taken as response variables. The response wear of $\mathrm{Al} / \mathrm{SiC} /$ rice husk ash MMCs can be expressed in terms of process parameters such as \% of $\mathrm{SiC}(\mathrm{S}), \%$ of rice husk ash $(\mathrm{R})$, load applied $(\mathrm{N})$, speed of rotation (V) and sliding distance (D) as

$$
\text { Wear, } \mathrm{T}=\psi(\mathrm{S}, \mathrm{R}, \mathrm{N}, \mathrm{V}, \mathrm{D})+\mathrm{e}_{\mathrm{u}}
$$

With 5 variables and five levels, the selected $1 / 2$ replicate central composite rotatable design consist of 32 experiments as shown in the table 4.

Table 3. Parameter levels in 5 factor design

\begin{tabular}{lcccccc}
\hline \multirow{2}{*}{ Process parameter } & Units & \multicolumn{5}{c}{ Parameter levels } \\
\cline { 3 - 7 } & & $\mathbf{- 2}$ & $\mathbf{- 1}$ & $\mathbf{0}$ & $\mathbf{1}$ & $\mathbf{2}$ \\
\hline \% SiC (S) & $\%$ & 2 & 4 & 6 & 8 & 15 \\
\% Rice husk ash (R) & m & 1.5 & 2 & 2.5 & 3 & 3.5 \\
Sliding speed (V) & $\mathrm{N}$ & 10 & 20 & 30 & 40 & 50 \\
Load (L) & $\mathrm{m}$ & 400 & 500 & 600 & 700 & 800 \\
Sliding distance (D) & & & & &
\end{tabular}

(i) The first 16 combination (1-16) of points given in the table constitute a $1 / 2$ replicate of $2^{5}$ factorial points comprises of code value of -1 or 1 of each parameter.

(ii) The next 10 combinations (17 - 26) of points given in the table is called a star points. These points are extra points incorporated to form a central composite design with $\beta=2^{(5-1) / 4}=2$.

(iii) The last 6 combinations $(27$ - 32) are replicated centre points added to give precision at the center. 
Table 4. $1 / 2$ replicate central composite rotatable experimental design and measured values

\begin{tabular}{|c|c|c|c|c|c|c|c|c|}
\hline \multirow{2}{*}{ S.No. } & \multicolumn{5}{|c|}{ Process parameters } & \multicolumn{2}{|c|}{ Wear rate $\mu \mathrm{m}$} & \multirow[b]{2}{*}{$\%$ error } \\
\hline & $\mathbf{S}$ & $\mathbf{R}$ & $\mathbf{V}$ & $\mathbf{L}$ & D & $\begin{array}{c}\text { Observed } \\
\text { Value } \\
\end{array}$ & $\begin{array}{c}\text { Predicted } \\
\text { Value } \\
\end{array}$ & \\
\hline 1 & -1 & -1 & -1 & -1 & 1 & 170.79 & 163.796 & 4.10 \\
\hline 2 & 1 & -1 & -1 & -1 & -1 & 87.92 & 83.636 & 4.87 \\
\hline 3 & -1 & 1 & -1 & -1 & -1 & 124.06 & 121.038 & 2.44 \\
\hline 4 & 1 & 1 & -1 & -1 & 1 & 135.04 & 128.374 & 4.94 \\
\hline 5 & -1 & -1 & 1 & -1 & -1 & 189.02 & 191.306 & -1.21 \\
\hline 6 & 1 & -1 & 1 & -1 & 1 & 140.51 & 147.446 & -4.94 \\
\hline 7 & -1 & 1 & 1 & -1 & 1 & 163.65 & 162.872 & 0.48 \\
\hline 8 & 1 & 1 & 1 & -1 & -1 & 180.33 & 177.860 & 1.37 \\
\hline 9 & -1 & -1 & -1 & 1 & -1 & 189.44 & 189.876 & -0.23 \\
\hline 10 & 1 & -1 & -1 & 1 & 1 & 179.28 & 170.328 & 4.99 \\
\hline 11 & -1 & 1 & -1 & 1 & 1 & 147.76 & 140.870 & 4.66 \\
\hline 12 & 1 & 1 & -1 & 1 & -1 & 189.63 & 180.170 & 4.99 \\
\hline 13 & -1 & -1 & 1 & 1 & 1 & 171.23 & 174.794 & -2.08 \\
\hline 14 & 1 & -1 & 1 & 1 & -1 & 113.6 & 118.946 & -4.71 \\
\hline 15 & -1 & 1 & 1 & 1 & -1 & 109.96 & 111.464 & -1.37 \\
\hline 16 & 1 & 1 & 1 & 1 & 1 & 136.53 & 143.112 & -4.82 \\
\hline 17 & -2 & 0 & 0 & 0 & 0 & 164.35 & 165.532 & -0.72 \\
\hline 18 & 2 & 0 & 0 & 0 & 0 & 132.64 & 138.996 & -4.79 \\
\hline 19 & 0 & -2 & 0 & 0 & 0 & 165.36 & 163.892 & 0.89 \\
\hline 20 & 0 & 2 & 0 & 0 & 0 & 139.29 & 145.300 & -4.31 \\
\hline 21 & 0 & 0 & -2 & 0 & 0 & 184.04 & 175.082 & 4.87 \\
\hline 22 & 0 & 0 & 2 & 0 & 0 & 196.21 & 187.510 & 4.43 \\
\hline 23 & 0 & 0 & 0 & -2 & 0 & 125.9 & 128.730 & -2.25 \\
\hline 24 & 0 & 0 & 0 & 2 & 0 & 146.33 & 142.038 & 2.93 \\
\hline 25 & 0 & 0 & 0 & 0 & -2 & 101.26 & 106.154 & -4.83 \\
\hline 26 & 0 & 0 & 0 & 0 & 2 & 119.83 & 120.478 & -0.54 \\
\hline 27 & 0 & 0 & 0 & 0 & 0 & 139.27 & 135.384 & 2.79 \\
\hline 28 & 0 & 0 & 0 & 0 & 0 & 140.37 & 135.384 & 3.55 \\
\hline 29 & 0 & 0 & 0 & 0 & 0 & 141.29 & 135.384 & 4.18 \\
\hline 30 & 0 & 0 & 0 & 0 & 0 & 128.99 & 135.384 & -4.96 \\
\hline 31 & 0 & 0 & 0 & 0 & 0 & 129.86 & 135.384 & -4.25 \\
\hline 32 & 0 & 0 & 0 & 0 & 0 & 131.51 & 135.384 & -2.95 \\
\hline
\end{tabular}


The range of upper limit and lower limit of the each parameters are coded as +2 and -2 respectively, and for in-between were evaluated from the equation (5) given below [31].

$$
\mathrm{X}_{\mathrm{i}}=\frac{2(2 X-(X \max -X \min ))}{(X \max -X \min )}
$$

Where $X_{i}$ is the coded values of the process variable $X, X$ is the value of the process variable inbetween the range of $X_{\min }$ to $X_{\max }, X_{\min }$ is the lower limit of the variable and $X_{\max }$ is the upper limit if the variable. The in-between values are coded as $-1,0$ and 1 .

\subsection{Wear test}

The tribological behaviour of the prepared specimens was analyzed by conducting dry sliding wear test as per the central composite experimental design. The synthesized MMCs specimens were subjected to wear test with varying wear parameters such as sliding speed, load and sliding distance. The wear tests were conducted under dry sliding condition using pin on disc apparatus as shown in the figure 2 according to the ASTM: G99-05 standard. The contact surface of the prepared specimen should be flat and uniform in order to have contact with rotating disk. The rotating disk was made of stainless steel of hardness $67 \mathrm{HRC}$. The pin is pressed against the rotating disk by applying load through counter weight balance. The weight attached to the counter was varied at five levels based on the experimental design. The sliding speed of the rotating disk and the sliding distance was also varied as per design plan. A LVDT attached to the level arm that hold pin on one side and counter on other side measures the displacement of the arm. The displacement is then calibrated and the wear is measured. The weight loss of the specimen was also measured before and after conducting each wear test. The observed and calibrated value of the wear during each test were recorded and noted in the table 4 . 


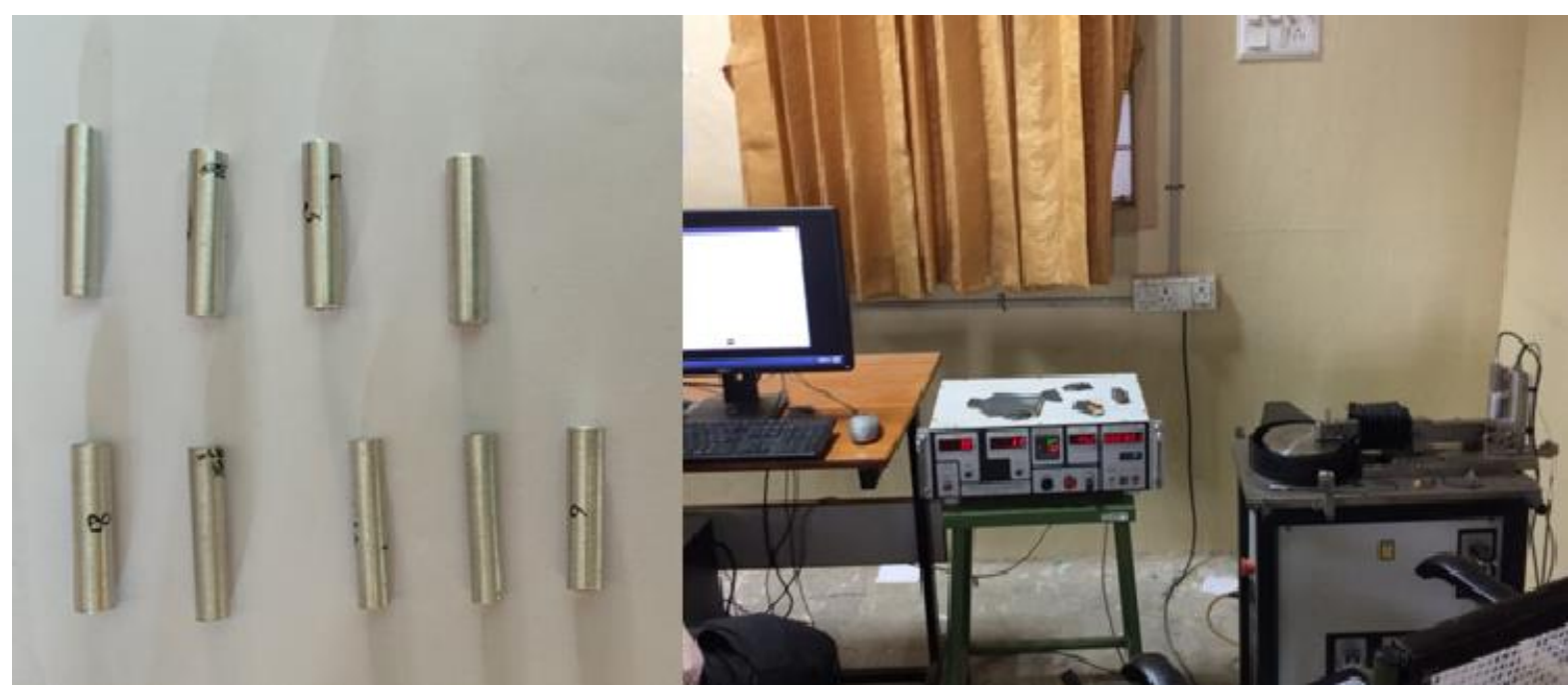

Figure 2. Prepared specimen and Pin on disc wear tester

\subsection{Predictive statistical model}

The coefficients of quadratic polynomials of the equation 2 can be calculated using multiple regression method. The values of the coefficient were calculated using statistical software QA Six Sigma DOEPC IV. The quadratic statistical model was developed by neglecting the insignificant coefficients. The developed model to predict wear $(\mathrm{W})$ is given by

Wear, $\mathrm{W}=135.384-6.634 \mathrm{~S}-4.648 \mathrm{R}+3.107 \mathrm{~V}+3.327 \mathrm{~L}+3.581 \mathrm{D}+4.22 \mathrm{~S}^{2}+4.803 \mathrm{R}^{2}+$

$$
11.478 \mathrm{~V}^{2}-5.517 \mathrm{D}^{2}+18.293 \mathrm{SR}+6.078 \mathrm{SL}-5.143 \mathrm{RL}-5.494 \mathrm{RD}-19.723 \mathrm{VL}
$$

Where $\mathrm{S}=\%$ of $\mathrm{SiC}, \mathrm{G}=\%$ of Rice husk ash, $\mathrm{V}=$ sliding speed in $\mathrm{m} / \mathrm{s}, \mathrm{L}=$ load in $\mathrm{N}$ and $\mathrm{D}=$ sliding distance in $\mathrm{m}$.

The ability of the model to predict accurately was tested using analysis of variance (ANOVA) technique. F and R ratio were used to check the adequacy of the model. F-ratio value is calculated as ratio between lack of fit sum of squares (degrees of freedom) to pure error sum of squares (degrees of freedom). R-ratio value is calculated as ratio between factors sum of squares (degrees of freedom) to pure error sum of squares (degrees of freedom). According to ANOVA analysis, for statistical empirical model to be adequate, the estimated value of F-ratio of the model developed should not be greater than the standard value of F-ratio and the estimated value of Rratio of the model developed should be greater than the standard value of R-ratio for a desired level of confidence. The adequacy of the statistical model is given in the table 4 . The estimated 
value of F-ratio of the model is less than the standard value and the estimated value of R-ratio is more than the standard value for a desired $95 \%$ level of confidence. The error between the observed values from experiments and predicted values from the equation 6 is found to be less than $5 \%$. This is evident that the equation derived is capable of prediction to the near accurate value.

Table 5. ANOVA - adequacy of the derived equations

\begin{tabular}{ccccccccc}
\hline & \multicolumn{3}{c}{ Degrees of freedom } & \multicolumn{2}{c}{ F- ratio } & \multicolumn{2}{c}{ R- ratio } & \multirow{2}{*}{$\begin{array}{c}\text { Adequate/ } \\
\text { Inadequate }\end{array}$} \\
\cline { 2 - 7 } & Factors & $\begin{array}{c}\text { Lack of } \\
\text { fit }\end{array}$ & $\begin{array}{c}\text { Pure } \\
\text { error }\end{array}$ & Model & Standard & Model & Standard & \\
\hline Wear & 14 & 12 & 5 & 4.271 & 4.68 & 46.469 & 4.62 & Adequate \\
\hline
\end{tabular}

Confirmatory experiments were conducted to validate the accuracy of the empirical model developed. A new set of levels of process parameters were selected for conducting the confirmatory experiments. The observations of the response wear of the confirmatory experiments were presented in the table 5. The percentage error between the experimental observation and the predicted value using empirical model was found to be less than 5\%. Thus from the confirmatory experiments, it was established that the developed model was capable to predict the wear of the composites with reasonable accuracy.

Table 6. Confirmatory experiments

\begin{tabular}{ccccccccr}
\hline \multirow{2}{*}{ S.No } & \multicolumn{4}{c}{ Process parameters } & \multicolumn{2}{c}{ Wear $(\boldsymbol{\mu m})$} & \multirow{2}{*}{ \% } \\
\cline { 2 - 8 } & $\mathbf{S}$ & $\mathbf{R}$ & $\mathbf{V}$ & $\mathbf{L}$ & $\mathbf{D}$ & Observed & Predicted & \\
\hline 1 & 2 & 0 & -2 & 1 & -1 & 219.67 & 224.525 & -2.21 \\
2 & 0 & 2 & 1 & -1 & -2 & 187.22 & 179.313 & 4.22 \\
3 & -1 & -2 & 0 & 2 & 1 & 240.99 & 235.454 & 2.30 \\
4 & -2 & 1 & -1 & 0 & 2 & 107.61 & 111.578 & -3.69 \\
\hline
\end{tabular}

\section{Results and discussion}

The developed statistical model was used to envisage wear by substituting the particular values of the input process parameters. The effect of these process parameters on wear of MMCs was studied using the developed empirical model. 


\subsection{Direct effect of process parameters on wear}

The direct effect of input parameters such as $\% \mathrm{SiC}, \%$ rice husk ash, speed of rotation of disc, load and sliding distance on wear were studied using the statistical empirical model. The direct effect was studied by varying levels of one process parameter whose effect need to be studied and the remaining parameter are kept at the middle level. The direct effect of input process parameter on wear were manipulated and plotted are shown in the figure 3 . The cause and effect of each process parameter on wear were analyzed and discussed below.

Figure 3 (a) shows the effect of $\% \mathrm{SiC}$ on wear. From the figure, it can be inferred that wear decreases with increase in $\% \mathrm{SiC} 3 \%$ to $12 \%$ and slight increase in wear is observed when $\% \mathrm{SiC}$ changes from $12 \%$ to $15 \%$. The figure illustrates wear properties of the prepared MMCs as the function of $\%$ of $\mathrm{SiC}$. In this case, the wear mechanism is predominantly by adhesion and delamination of reinforced particles. Since $\mathrm{SiC}$ particles possesses good wear resistance and high hardness, its addition of $\mathrm{SiC}$ leads to an enhancement in the wear resistance. The hard $\mathrm{SiC}$ particles act as a knob on the reinforced surfaces and protect soft aluminium matrix from the interface of steel disc. Also the improved interfacial bonding between $\mathrm{Al}$ alloy and $\mathrm{SiC}$ particle reinforcement raises the plastic shear strain of the material which in turn enhances wear resistance of composite. It is evident from the figure the wear loss reduces with an increase in \% of $\mathrm{SiC}$ particles from $3 \%$ to $12 \%$. The wear loss slightly increases when $\%$ of $\mathrm{SiC}$ particles increases to $15 \%$, due to the porosity contribution.

The effect of \% rice husk ash particles on the wear loss of the composite is depicted in the figure 3 (b). The graph shows that the loss of material due to sliding wear decreases with an increase in $\%$ of rice husk ash in MMCs from 2\% to $6 \%$. From $6 \%$ to $8 \%$, the wear loss don't show any significant change as it is in the same level. A slight increase in wear is observed when the $\%$ of rice husk ash increase from $8 \%$ to $10 \%$. Addition of rice husk ash reduces wear rate due to its inherent wear resistance properties. This can be exhibited from the graph the wear loss decreases with an increase in $\%$ of rice husk ash. It can be concluded that the wear loss is minimum when the \% of rice husk ash in the MMCs is between 6\% - 8\%. 


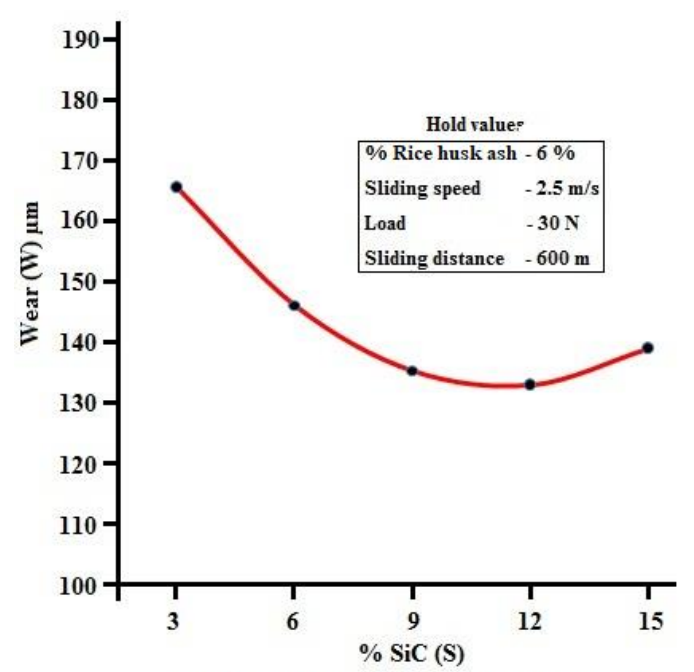

Figure 3 (a) Direct effect of $\% \mathrm{SiC}$ on wear

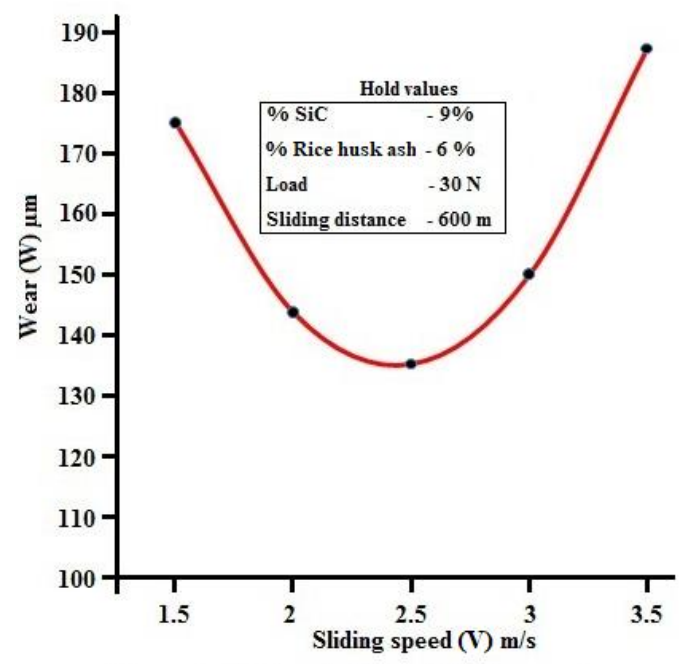

Figure 3 (c) Direct effect of sliding speed on wear

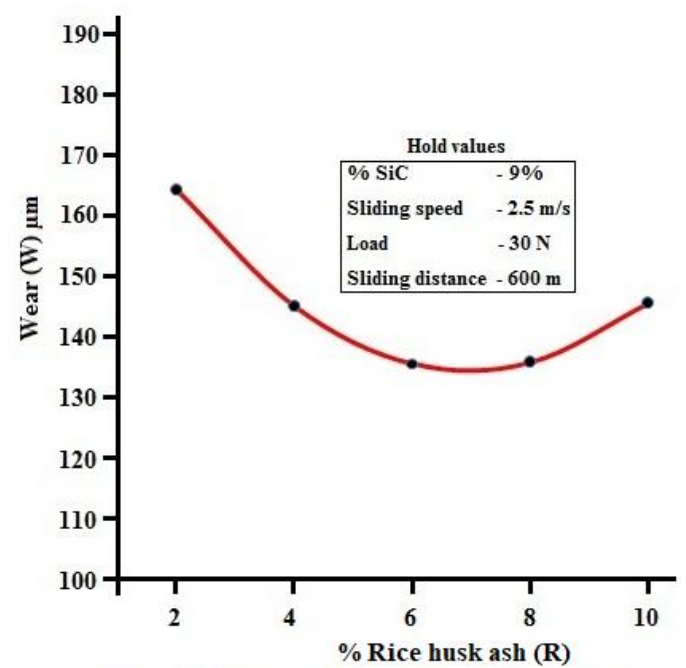

Figure 3 (b) Direct effect of \%Rice husk ash on wear

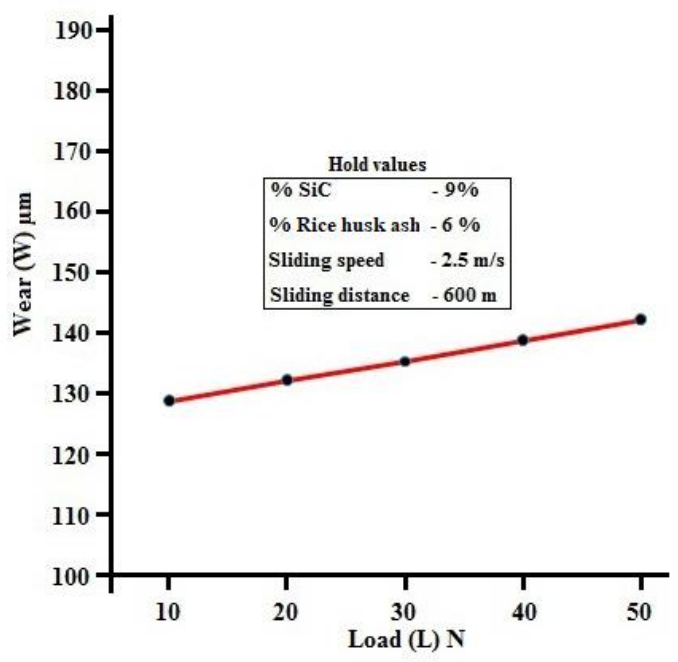

Figure 3 (d) Direct effect of load on wear

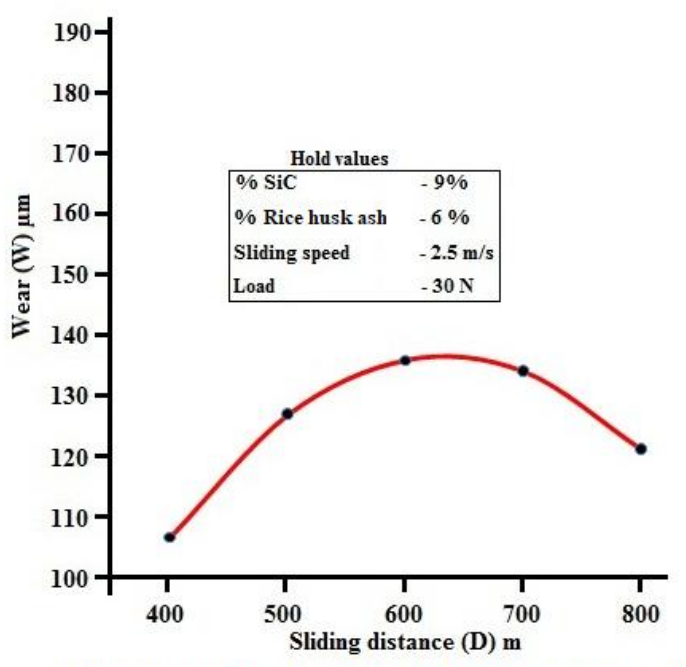

Figure 3 (e) Direct effect of sliding distance on wear

Figure 3. Direct effect of process parameters on wear 
The dependency of wear loss with respect to sliding speed is presented in the figure 3 (c). It is observed form the graph that the wear loss decreases with an increase in sliding speed from 1.5 $\mathrm{m} / \mathrm{s}$ to $2.5 \mathrm{~m} / \mathrm{s}$ and then the wear loss increases with an increase in sliding speed from $2.5 \mathrm{~m} / \mathrm{s}$ to $3.5 \mathrm{~m} / \mathrm{s}$. The strain rate get increases and interaction between mating surface decrease with increase in sliding speed, which results in lower wear loss. This phenomenon exhibited when the sliding speed increased from $1.5 \mathrm{~m} / \mathrm{s}$ to $2.5 \mathrm{~m} / \mathrm{s}$. At lower speed the wear loss is by means of abrasion and at higher speed the adhesion becomes prominent in wear loss. Thus, when sliding speed increases from $2.5 \mathrm{~m} / \mathrm{s}$ to $3.5 \mathrm{~m} / \mathrm{s}$, the wear loss of the MMCs increases.

Figure 3 (d) depicts the effect of load on wear. The graph shows that there was an increase in the wear loss with an increase in load from $10 \mathrm{~N}$ to $50 \mathrm{~N}$. In this process abrasive wear mechanism is dominant phenomenon by which wear takes place during sliding. The contact pressure is minimal at low load, which increases with an increase in the load. As a result more amout of wear take place due to the addtion of load. The debris fromed during sliding cram between the surafce of sliding resulting in more wear loss. During wear test, the same conslusion were arrived, the plotted graph depicts an incresing trend for wear loass with an increase in load.

Figure 3 (e) shows the effect of sliding distance on wear. It is understandable from the graph that the wear increases with an increase sliding distance from $400 \mathrm{~m}$ to $600 \mathrm{~m}$ and then slight decrease in wear with an increase in sliding distance to $700 \mathrm{~m}$ and $800 \mathrm{~m}$. The increase in wear may due to increase in surface area of contact as sliding distance increases. A slight decrease in wear at a sliding distance to $700 \mathrm{~m}$ and $800 \mathrm{~m}$ may due to oxide formation in the interface.

\subsection{Interaction of process parameters on wear}

The interaction effect aims in studying the change in influence of one process parameter on the response, while the second process parameter is changed from one level to another and the remaining process parameters are kept at the middle level. This analysis helps to understand the wear behaviour of fabricated MMCs when two parameters are considered at a time. The interaction effect of process parameters which have strong influence with wear of MMCs were manipulated and plotted are shown in the figure 4. 


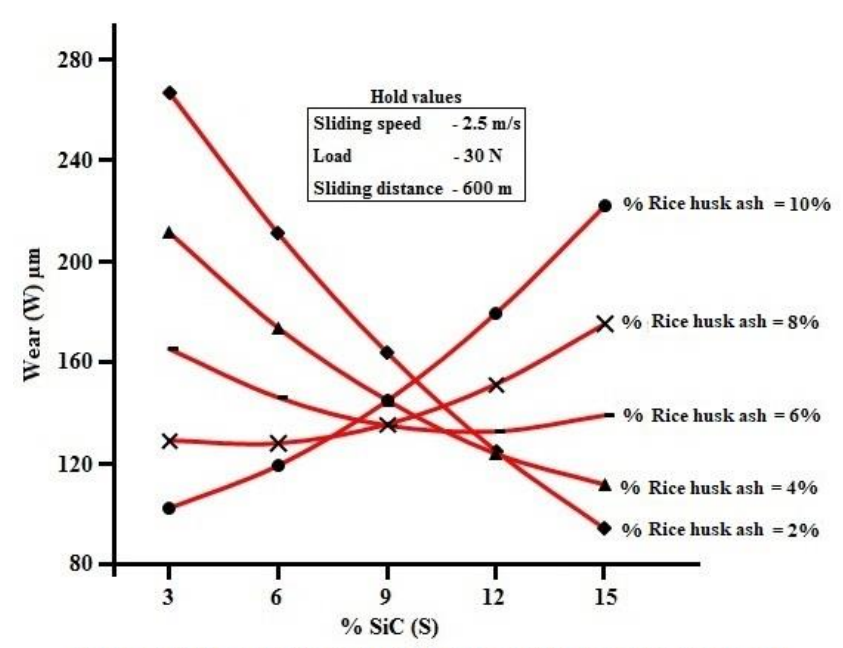

Figure 4 (a) Interaction effect of $\% \mathrm{SiC}$ and rice husk ash on wear

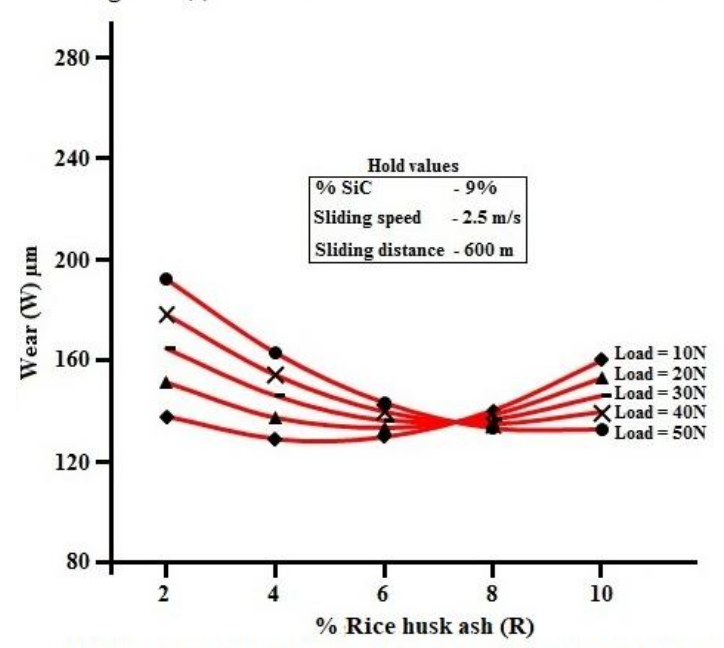

Figure 4 (c) Interation effect of \% Rice husk ash and load on wear

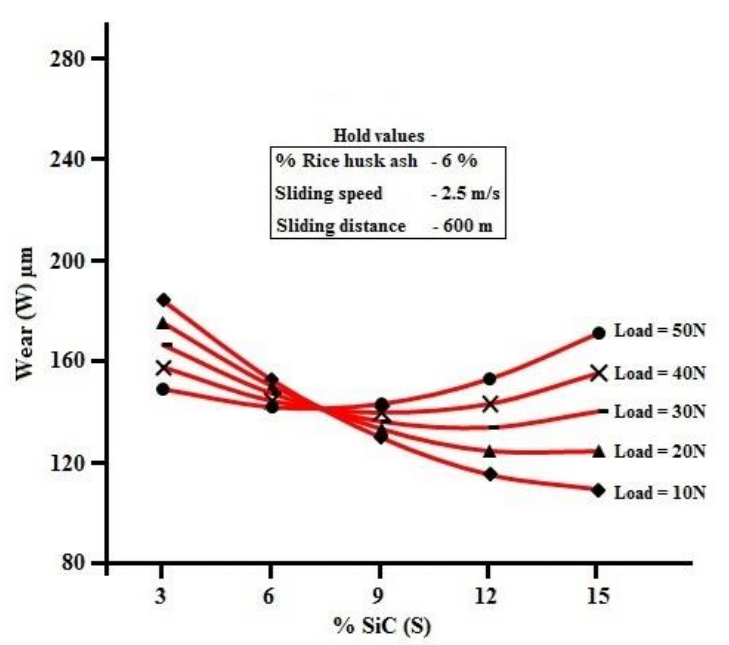

Figure 4 (b) Interaction effect of $\% \mathrm{SiC}$ and load on wear

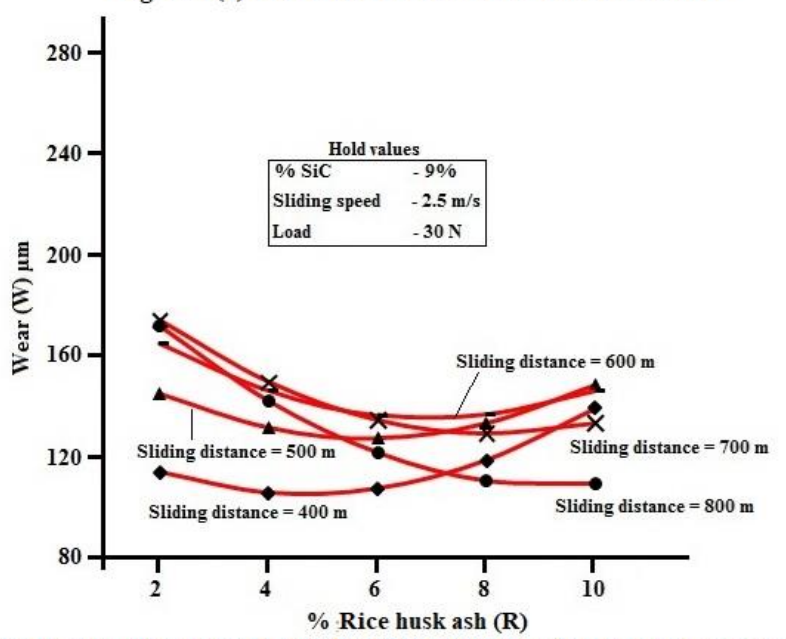

Figure 4 (d) Interaction effect of $\%$ Rice husk ash and sliding distance on wear

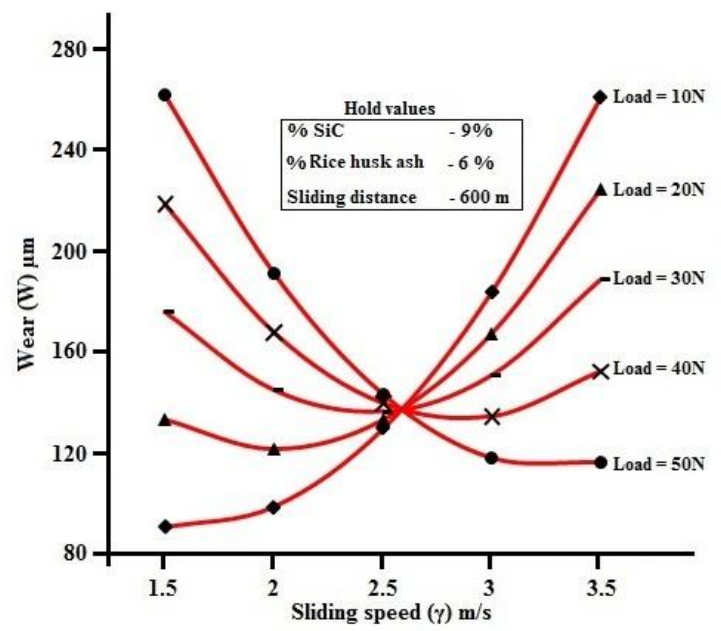

Figure 4 (e) Interation effect of sliding speed and load on wear

Figure 4. Interaction effect of process parameters on wear 
Figure 4(a) shows the interaction effect of $\% \mathrm{SiC}$ and \%rice husk ash on wear of composites. It reveals that an increase in $\% \mathrm{SiC}$ particulate in composite exhibit a decrease in wear, when the $\%$ rice husk is at the lower level i.e., for $2 \%$. The same trend continues for the change level of $\%$ rice husk rusk of $4 \%$ and $6 \%$. But the trend get reversed at higher level of \%rice husk ash (for $8 \%$ and $10 \%$ ), increase in $\% \mathrm{SiC}$ particulate exhibit a decrease in wear.

The interaction effect of $\% \mathrm{SiC}$ and load on wear is shown in the figure 4(b). The graph reveals that an increase in $\% \mathrm{SiC}$ exhibit a decrease in wear, when the load is at the level at $10 \mathrm{~N}$ and 20 $\mathrm{N}$. The trend gradually changes at the level of load at $30 \mathrm{~N}$, where an increase in $\% \mathrm{SiC}$ from $3 \%$ to $12 \%$ resulted in decrease in wear and a slight increase in wear exhibited at $15 \% \mathrm{SiC}$. Similar trend was observed in the case of load at $40 \mathrm{~N}$ and $50 \mathrm{~N}$, where a slight increase in $\% \mathrm{SiC}$ from $3 \%$ to $6 \%$ resulted in decrease in wear and increase in wear is observed with an increase of $\% \mathrm{SiC}$ at $9 \%, 12 \%$ and $15 \%$.

The interaction effects of \%Rice husk ash and load on wear is indicated in the figure 4(c). The plot indicates that for the level of load of $10 \mathrm{~N}$, an increase in \%Rice husk ash resulted in decrease of wear. For the levels of load of $20 \mathrm{~N}$ and $30 \mathrm{~N}$, an increase in \%Rice husk ash from $2 \%$ to $8 \%$ resulted in decrease of wear and at $10 \%$ Rice husk ash, slight decrease in wear exhibited. The similar trend is observed at last two levels of load, an increase in \%Rice husk ash, for $2 \%$, $4 \%$ and $6 \%$ resulted in decreased wear and an increase in \%Rice husk ash, for $8 \%$ and $10 \%$ resulted in increased wear.

Figure 4(d) depicts the interaction effect of \% rice husk ash and sliding distance on wear of MMCs. The graph indicates that for the level of sliding distance of $400 \mathrm{~m}$ and $500 \mathrm{~m}$, an increase in $\%$ rice husk ash at $2 \%$ resulted in decrease of wear and an increase in $\%$ rice husk ash at $4 \%$, $6 \%, 8 \%$ and $10 \%$ resulted an increase in wear. The trend slightly changes for the sliding distance of $600 \mathrm{~m}$, where an increase in $\%$ rice husk ash at $2 \%, 4 \%$ resulted in decrease of wear and an increase in $\%$ rice husk ash at $6 \%, 8 \%$ and $10 \%$ resulted an increase in wear. The trend drastically changes for a sliding distance of $700 \mathrm{~m}$ and $800 \mathrm{~m}$, an increase in $\%$ rice husk ash for all the levels resulted in decrease of wear.

Figure 4(e) shows the interaction effect of sliding speed and load on wear. From the figure it is understood that the wear increases with an increase in sliding speed for the level of load at $10 \mathrm{~N}$. 
For the change of level of load at $20 \mathrm{~N}$, the wear decreases with an increase in sliding speed from $1.5 \mathrm{~m} / \mathrm{s}$ to $2 \mathrm{~m} / \mathrm{s}$ and then increases from $2 \mathrm{~m} / \mathrm{s}$ to $3.5 \mathrm{~m} / \mathrm{s}$. For the change of level of load at $30 \mathrm{~N}$, the trend slightly changes as the wear decreases with an increase in sliding speed from $1.5 \mathrm{~m} / \mathrm{s}$ to $2.5 \mathrm{~m} / \mathrm{s}$ and then increases from $2.5 \mathrm{~m} / \mathrm{s}$ to $3.5 \mathrm{~m} / \mathrm{s}$. For the change of level of load at $40 \mathrm{~N}$, the trend slightly reverses as the wear decreases with an increase in sliding speed from $1.5 \mathrm{~m} / \mathrm{s}$ to 3 $\mathrm{m} / \mathrm{s}$ and then increases from $3 \mathrm{~m} / \mathrm{s}$ to $3.5 \mathrm{~m} / \mathrm{s}$. For the change of level of load at $50 \mathrm{~N}$, the trend completely reversed as the wear decreases with an increase in sliding speed.

\subsection{Microstructure examination}

For microscopic analysis, the samples were sectioned to the required size using precession cutting machine and mounted on the mould using M-seal as shown in the figure 5. The standard metallographic procedure were followed for microstructure examination. The surface of the samples were prepared using emery abrasive sheet of various grit size, polished using disc polishing machine with alumina and etched using Keller's reagent. The microstructure of the MMCs were examined and analysed using optical microscope under 100x magnification. The microstructure of unreinforced Al7075 is depicted in the figure 6. It is found from the unreinforced sample of Al7075, the alloying elements are precipitated and are distributed and dispersed uniformly.

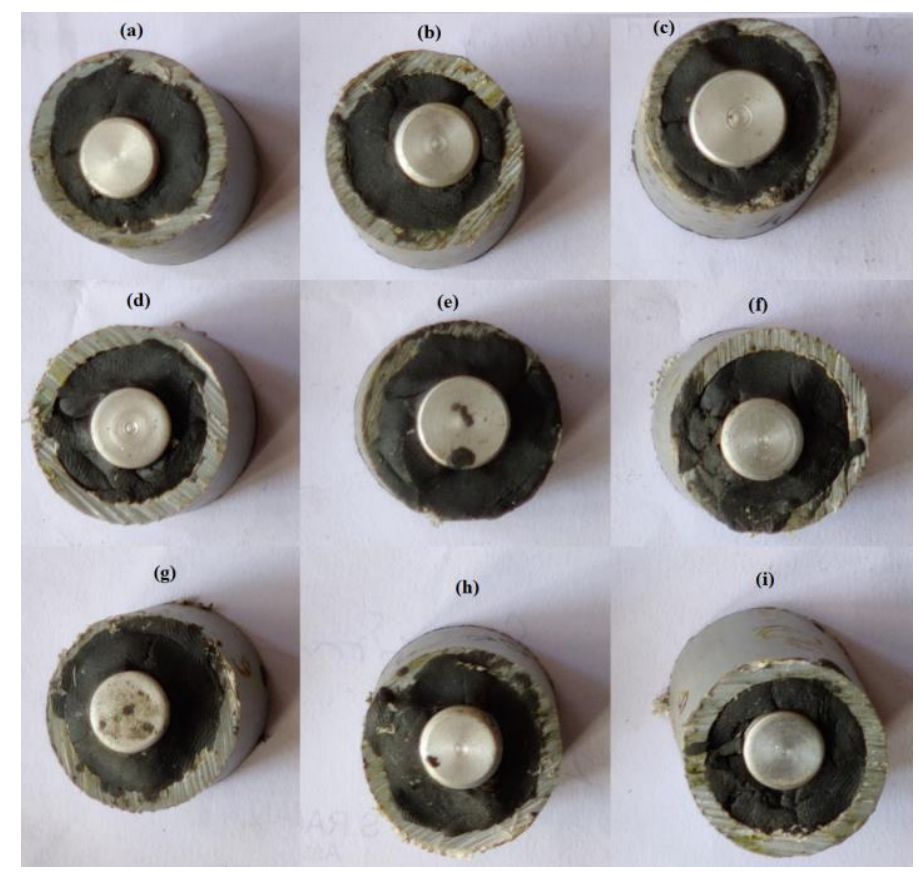

Figure 5. Samples for microscopic analysis 


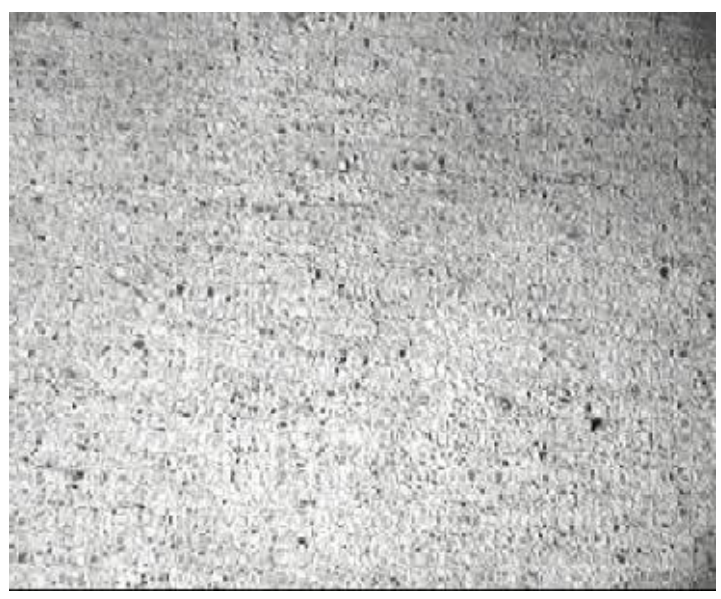

Figure 6. Microstructure of A17075
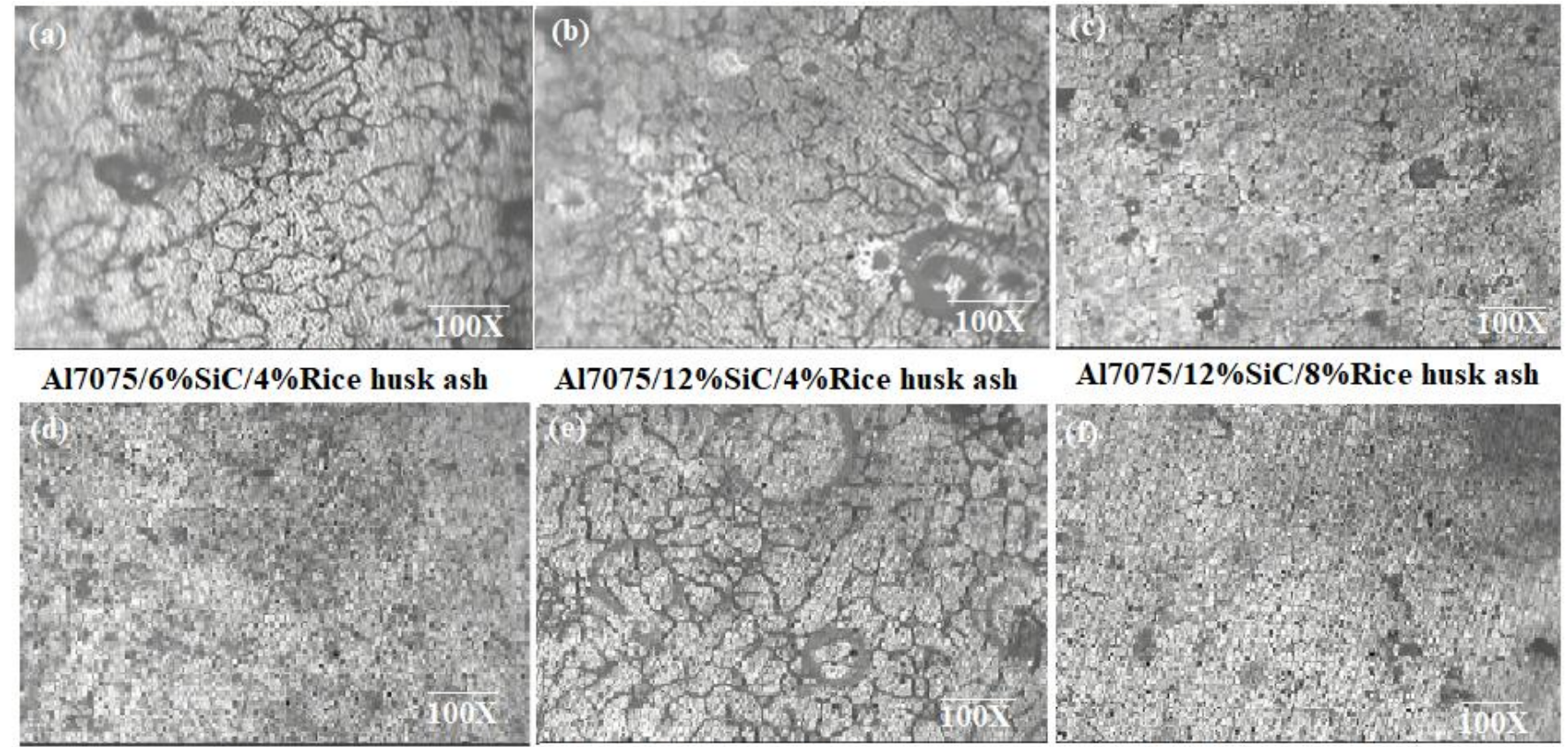

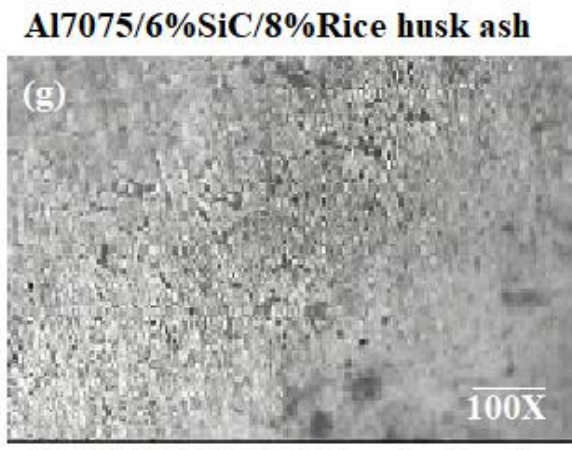

Al7075/9\%SiC/2\%Rice husk ash

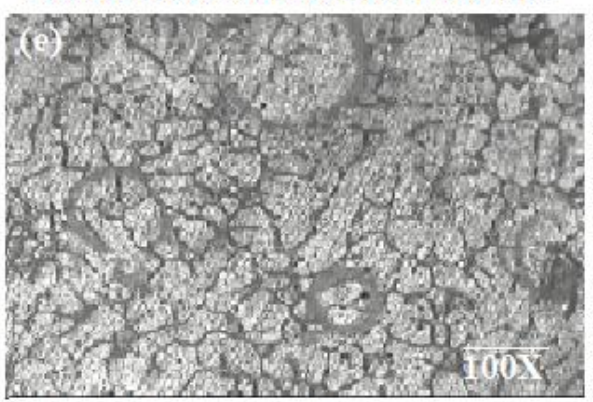

Al7075/3\%SiC/6\%Rice husk ash

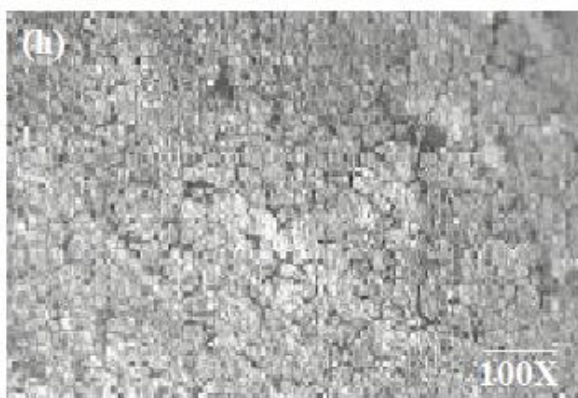

Al7075/9\%SiC/10\%Rice husk ash

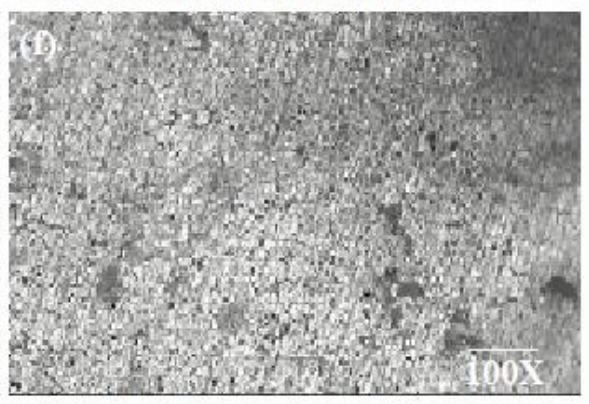

Al7075/15\%SiC/6\%Rice husk ash

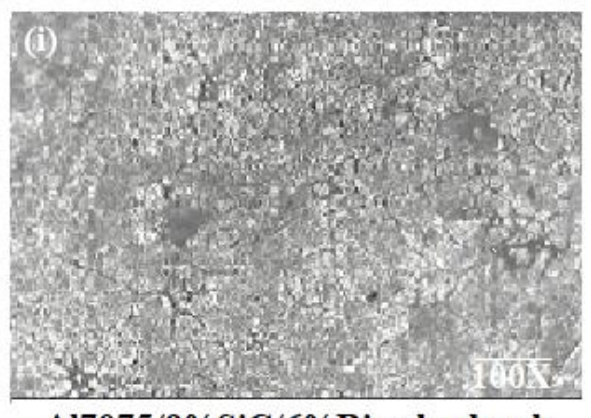

Al7075/9\%SiC/6\%Rice husk ash

Figure 7. Microstructure of Al7075/SiC/Rice husk ash 
The fabricated MMCs to have better quality and enhancement in mechanical properties, uniform distribution of reinforcement particulate in matrix material is essential. The microstructure of different combination of MMCs fabricated for this study is examined and depicted in the figure 7. Figure 7 (a-i) indicates that the $\mathrm{SiC}$ and rice husk ash of various percentage combination are dispersed uniformly in the Al7075 matrix material. For figure 7 (a) of Al/6\%SiC/4\%rice husk ash, figure 7 (b) of $\mathrm{Al} / 12 \% \mathrm{SiC} / 4 \%$ rice husk ash, figure 7 (e) of $\mathrm{Al} / 3 \% \mathrm{SiC} / 6 \%$ rice husk ash and figure $7(\mathrm{~g})$ of $\mathrm{Al} / 9 \% \mathrm{SiC} / 2 \%$ rice husk ash, the $\mathrm{SiC}$ particles reinforcement are distributed uniformly and rice husk ash form a cluster in random pattern and fragment flake distribution uniformly in the composite. The improper accumulated cluster form of rice husk ash is due to improper stirring speed and insufficient temperature of casting. Lower percentage of reinforcement in composite resulted in developing porosity due obstruction in fluidity of molten metal resulting in clustering around porous content. For figure 7 (d) of $\mathrm{Al} / 6 \% \mathrm{SiC} / 8 \%$ rice husk ash, figure 7 (h) of $\mathrm{Al} / 9 \% \mathrm{SiC} / 10 \%$ rice husk ash and figure 7 (i) of $\mathrm{Al} / 9 \% \mathrm{SiC} / 6 \%$ rice husk ash, $\% \mathrm{SiC}$ reinforcement creates an agglomeration of particles which strengthen the fabricated MMCs. Higher percentage of rice husk ash exhibits more even distribution and avoids voids formation and micro cracks. For figure 7 (c) of $\mathrm{Al} / 12 \% \mathrm{SiC} / 8 \%$ rice husk ash and figure 7 (f) of $\mathrm{Al} / 15 \% \mathrm{SiC} / 6 \%$ rice husk ash, higher $\% \mathrm{SiC}$ reinforcement generates more agglomeration results in high strength casted material and better bonded with the aluminium matrix material. SiC particles and rice husk ash are uniformly distributed and resulting in good mechanical bonding.

\section{Optimization of process parameter}

Genetic algorithm (GA) is a nondeterministic influential technique used in search and optimization of problems defining process with discrete independent variables [37, 38]. It stress upon genetic coding of possible solutions into chromosomes and uses genetic operators to these chromosomes. A standard GA uses binary representation, crossover of bitwise binary representation and bit flipping mutation. The basic principle of genetic algorithm is based on survival of the fittest concept which state that among population, only fittest individuals have high chance to reproduce and succeed for the next generation. The GA operators adapted to arrive solution are reproduction, crossover and mutation. The outline of standard GA are described below, 
i. Create the primary population at random using coding to represent process parameters, a crossover operator with probability and a mutation probability with probability. The maximum allowable generation number to succeed is 100 .

ii. Determine the fitness of the each individual in the succeeding populations

iii. Select parents form the succeeding population based on the fitness function. The selection type decides the probability of an individual being selected for reproducing offspring's by crossover and mutation.

iv. Perform crossover with probability to selected pair of parents and mutation with probability to crossover new individuals

v. Evaluate by replacing parents by the offspring in the population to produce new generation

vi. Repeat the steps ii to $\mathrm{v}$ until the halting criterion satisfied.

The optimization aims to find the best value for the response out of the number of possible combinations of variables that defines the problem mathematically. In this study, the objective is to minimize wear in MMCs. The objective function is the empirical equation (equation 6) developed can be used along with constrains as range of each parameters such as $\%$ of $\mathrm{SiC}, \%$ of rice husk ash, speed of rotation of disc, load and sliding distance to minimize wear.

Minimize Wear, $\mathrm{W}=135.384-6.634 \mathrm{~S}-4.648 \mathrm{R}+3.107 \mathrm{~V}+3.327 \mathrm{~L}+3.581 \mathrm{D}+4.22 \mathrm{~S}^{2}+$ $4.803 \mathrm{R}^{2}+11.478 \mathrm{~V}^{2}-5.517 \mathrm{D}^{2}+18.293 \mathrm{SR}+6.078 \mathrm{SL}-5.143 \mathrm{RL}-5.494 \mathrm{RD}-19.723 \mathrm{VL}$

Subjected to

$$
-2 \leq \mathrm{S}, \mathrm{R}, \mathrm{V}, \mathrm{L}, \mathrm{D} \leq 2
$$

Representation of each parameter through encoding is the first step in GA. Each process parameters ( $\mathrm{S}, \mathrm{R}, \mathrm{V}, \mathrm{L}$ and $\mathrm{D})$ are coded using bit-string structures which is a binary representation of continuous design variables. The individual bit string corresponds to genes and the values of the genes can take to alleles, which is merged to form a chromosome of certain length. The length of the chromosome chosen in this study for the process parameter is 8 bits. The decoding of length of chromosome includes decoding the individual genes into the corresponding values in the interval of 0 to 1 and then mapping that integer to the parameter interval values from minimum to maximum. The bit-string structures (00000000) and (11111111) represents the 
minimum and maximum values of process parameters values. By representing in bit-string structure only the grid points are searched and solution is assumed to be the grid point of smallest value of the objective function. The resolution (solution accuracy) of the grid points with the coding for the process parameters S, R, V, L and D are $0.046875^{\circ}, 0.03125^{\circ}, 0.0078125 \mathrm{~m} / \mathrm{s}$, $0.15625 \mathrm{~N}$ and $1.5625 \mathrm{~mm}$ respectively as shown in the table 7 .

Table 7. Resolution for the process parameters

\begin{tabular}{lcccc}
\hline Process parameters & Limits (Range) & Code & Decode & Resolution \\
\hline \% SiC (S) & $3^{0}-15^{0}\left(12^{0}\right)$ & 00000000 & 0 & $0.046875^{0}$ \\
& & 11111111 & 255 & \\
\% Rice husk ash (R) & $2^{0}-10^{0}\left(8^{0}\right)$ & 00000000 & 0 & $0.03125^{0}$ \\
& & 11111111 & 255 & \\
Sliding speed (V) & $1.5 \mathrm{~m} / \mathrm{s}-3.5 \mathrm{~m} / \mathrm{s}$ & 00000000 & 0 & $0.0078125 \mathrm{~m} / \mathrm{s}$ \\
& $(2 \mathrm{~m} / \mathrm{s})$ & 11111111 & 255 & \\
Load (L) & $10 \mathrm{~N}-50 \mathrm{~N}$ & 00000000 & 0 & $0.15625 \mathrm{~N}$ \\
& $(40 \mathrm{~N})$ & 11111111 & 255 & \\
Sliding distance (D) & $400 \mathrm{~mm}-800$ & 00000000 & 0 & $1.5625 \mathrm{~mm}$ \\
\hline
\end{tabular}

GA is based on survival of fittest principle, they are more suitable of maximizing the objective function [39]. In this study the objective function of minimization type, hence the given objective function is converted into maximization type by multiplying the entire equation by -1 . The selection process decides the probability of an individual being selected for reproducing offspring's by crossover and mutation. The selection type should facilitate in such a way that the fitter individual should have high probability of getting selected and unfit individuals should be selected in low probability. Roulette wheel selection scheme was employed to calculate the probability of section from the individual fitness value. The new generation population is augmented with better string from the earlier generation after reproduction. A crossover operator in used to generate better strings in the population. In GA, crossover probability select two parent strings at random form the mating pool and combined them by exchanging some portion of the strings to form a two new offspring's. Point crossover and uniform crossover are two general crossover operator used for integer strings. In this paper uniform crossover with probability of 
0.9 was used to populate new offspring's. A mutation operator is usually based on probability distribution such as normal, uniform and Cauchy distribution is a bit flipping operation for integer strings. In mutation, thorough bit flipping operation flips a bit from 1 to 0 and 0 to 1 based on mutation probability. In this paper bit flipping mutation with probability of 0.1 was used to mutate a new offspring's.

After deploying GA operators, a fresh set of population is generated. This entire process completes one generation of GA. Such iterations are continued till the termination criterion is achieved. The iteration is repeated for a population size of 100 for 100 generations. Then, they are decoded and objective function values are calculated. The above process is simulated by a computer program developed using $\mathrm{C}$ language for computations. Figure 8 shows the results obtained by simulating the $\mathrm{C}$ program of GA to determine minimum wear in each generations. It is clear from the figure that the minimum wear of composite occurs at the 62 generation and the value is $34.507 \mu \mathrm{m} \approx 34.5 \mu \mathrm{m}$. The optimum values of process parameters for minimum wear is given as, $\%$ of $\mathrm{SiC}=11.6629^{0} \approx 12^{0}, \%$ of rice husk ash $=7.2222^{0} \approx 7^{0}$, sliding speed $=1.908 \mathrm{~m} / \mathrm{s}$ $\approx 1.9 \mathrm{~m} / \mathrm{s}$, load $=11.522 \mathrm{~N} \approx 11.5 \mathrm{~N}$ and sliding distance $=714.75 \mathrm{~mm} \approx 715 \mathrm{~mm}$.

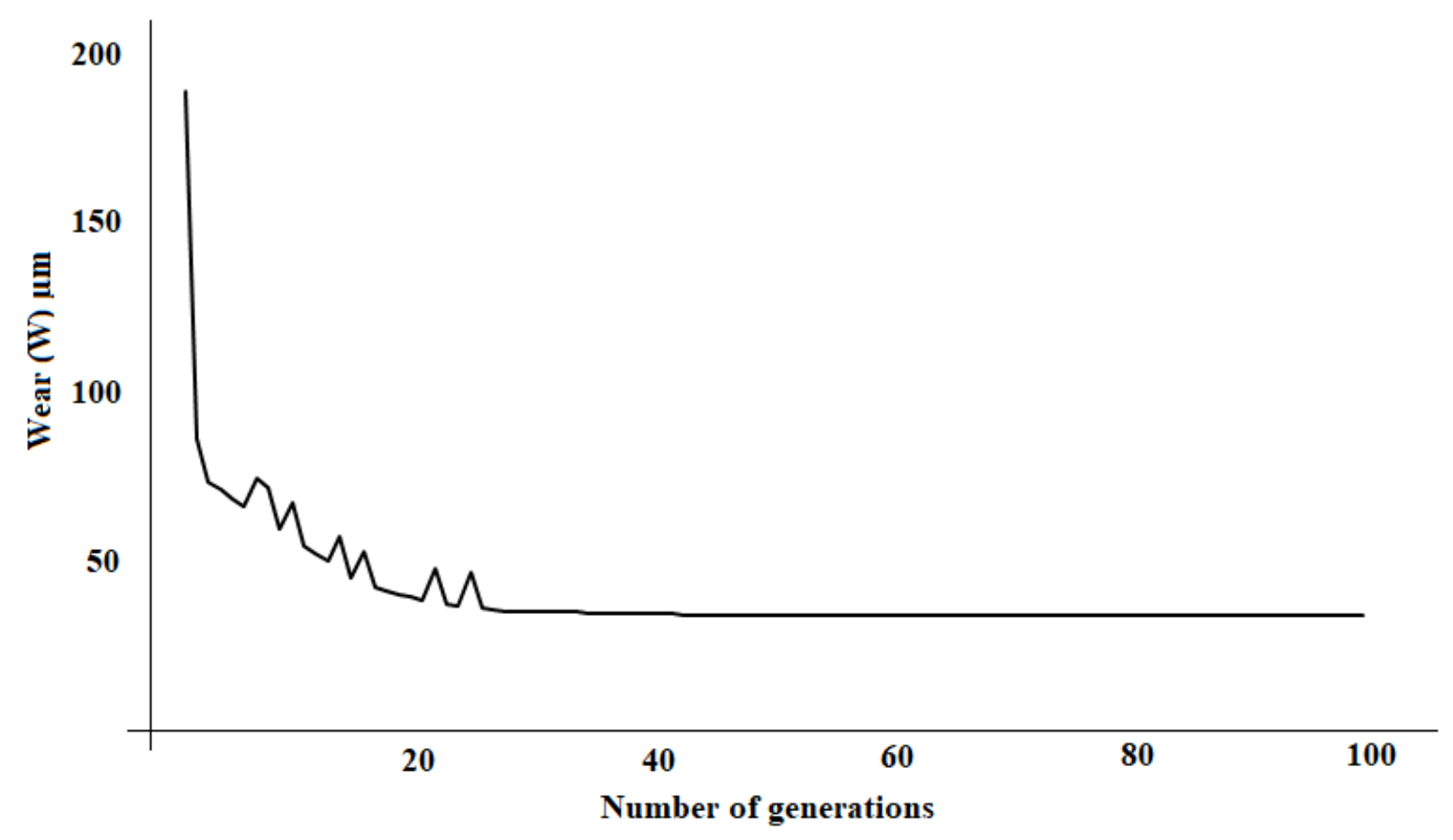

Figure 8. Variations of fitness value with number of generations for wear 


\section{Conclusion}

The experiments were conducted on hybrid MMCs to predict wear and to study the influence of process parameters such as \% of $\mathrm{SiC}, \%$ of rice husk ash, load applied, speed of rotation and sliding distance. The microstructure of fabricated composite materials were observed and analyzed. The following conclusions were obtained after detailed analysis and exploration.

1. A quadratic polynomial equation to predict wear of hybrid MMCs in terms process parameters such as \% of $\mathrm{SiC}, \%$ of rice husk ash, load applied, speed of rotation and sliding distance was developed using central composite rotatable second-order response surface methodology.

2. With different process parameters, both predicted values using empirical analytical model developed and experimental results shows good agreement.

3. Increase in levels of $\%$ of $\mathrm{SiC}$ form $3 \%$ to $12 \%$, increase in levels of $\%$ of rice husk ash from $2 \%$ to $8 \%$, increase in levels of sliding speed form $1.5 \mathrm{~m} / \mathrm{s}$ to $2.5 \mathrm{~m} / \mathrm{s}$, decrease in levels of load speed from $50 \mathrm{~N}$ to $10 \mathrm{~N}$ and decrease in sliding distance from $600 \mathrm{~m}$ to $400 \mathrm{~m}$ results in decrease in wear of fabricated MMCs.

4. The interaction effect of various parameters on wear were analyzed, and strong interactions were observed between $\%$ of $\mathrm{SiC}, \%$ of rice husk ash, load applied, speed of rotation and sliding distance.

5. The adequacy of the empirical equations developed was checked using ANOVA technique, validity of the model is checked by conducting conformity test.

6. The empirical model developed for prediction of wear can be further improved and used to optimize the process parameters using evolutionary algorithm.

7. The microstructure of fabricated MMCs reveals a uniform distribution of reinforcement particulate in matrix material which ensure better quality and enhancement in mechanical properties.

8. The genetic algorithm has been employed to optimize the process parameters to obtain the minimum wear in MMCs. The optimal combination of process for minimum wear of $34.5 \mu \mathrm{m}$ was found to be $12^{0}, 7^{0}, 1.9 \mathrm{~m} / \mathrm{s}, 11.5 \mathrm{~N}$ and $715 \mathrm{~mm}$ for $\%$ of $\mathrm{SiC}, \%$ of rice husk ash, sliding speed, load and sliding distance, respectively 


\section{Ethics approval and consent to participate}

The authors of this paper declare that all procedures followed were in accordance with the ethical standards.

This paper is our original unpublished work and assures that it has not been submitted to any other journal for reviews.

\section{- Disclosure of potential conflicts of interest}

There is no conflict of interest in this work.

- Research involving Human Participants and/or Animals

The research is involved in data collection form the mechanical device only, not involved in testing or implementing in humans/ animals

\section{- Informed consent}

The authors of this paper declare their consent to participate in this research article.

\section{Consent for publication}

The authors of this paper declare their consent to publish this research article in this journal.

\section{Availability of data and materials}

All authors declare that all data and materials as well as software application or custom code support their published claims and comply with field standards.

\section{Competing interests}

All authors declare that they have no conflict of interest

\section{Funding}

No funds, grants, or other support was received.

\section{Authors' contribution}

All authors of this paper have done equal contribution - conceptualization, investigations, devising methodology, analysis, writing and documenting. 


\section{References}

1. Deavaraju A, Kumar A, Kumaraswamy A, Kotiveerachari B (2013) Influence of reinforcements $\left(\mathrm{SiC}\right.$ and $\left.\mathrm{Al}_{2} \mathrm{O}_{3}\right)$ and rotational speed on wear and mechanical properties of aluminum alloy 6061-T6 based surface hybrid composites produced via friction stir processing, Materials and Design, 51: 331-341.

2. Rehman A, Das S, Dixit G (2012) Analysis of stir die cast Al- SiC composite brake drums based on coefficient of friction, Tribology International, 51: 36-41

3. Dolatkhah A, Golbabaei P, BesharatiGivi MK, Molaiekiya F (2012) Investigating effects of process parameters on microstructural and mechanical properties of Al5052/SiC metal matrix composite fabricated via friction stir processing, Materials and Design, 37: 458-464.

4. Du Yuan, Xiong Yang, Shusen Wu, Shulin Lu, Kun Hu (2019) Development of high strength and toughness nano-SiCp /A356 composites with ultrasonic vibration and squeeze casting, Journal of Materials Processing Technology, 269: 1-9.

5. Hodder KJ, Izadi H, McDonald AG, Gerlich AP (2012) Fabrication of aluminum-alumina metal matrix composites via cold gas dynamic spraying at low pressure followed by friction stir processing, Materials Science and Engineering A, 556: 114-121.

6. Yu JH, Wang CB, Zhang LM (2012) Preparation and properties of Sip/Al composites by spark plasma sintering, Materials and Design, 41: 198-202.

7. Yihao Wu, Ke Zhan, Zheng Yang, Wei Sun, Bin Zhao, Ya Yan, Junhe Yang (2019) Graphene oxide/Al composites with enhanced mechanical properties fabricated by simple electrostatic interaction and powder metallurgy, Journal of Alloys and Compounds 775: 233240.

8. Rajmohan T, Palanikumar K, Ranganathan S (2013) Evaluation of mechanical and wear properties of hybrid aluminium matrix composites, Transaction Nonferrous Metals Society of China 23: 2509-2517. 
9. Rao RN, Das S, Mondal DP, Dixit G (2012) Mechanism of material removal during tribological behaviour of aluminium matrix ( $\mathrm{Al}-\mathrm{Zn}-\mathrm{Mg}-\mathrm{Cu}$ ) composites, Tribology International, 53:179-184.

10. Baradeswarn A, Elaya Perumal A (2013) Influence of $B_{4} C$ on the tribological and mechanical properties of Al7075-B ${ }_{4} \mathrm{C}$ composites, Composites: Part B, 54: 146-152.

11. Nishant Verma, Vettivel SC (2018) Characterization and experimental analysis of boron carbide and rice husk ash reinforced AA7075 aluminium alloy hybrid composite, Journal of Alloys and Compounds 741: 981-998.

12. Pushyamitra Mishra, Priti Mishra, Rana RS (2018) Effect of Rice Husk ash Reinforcements on Mechanical properties of Aluminium alloy (LM6) Matrix Composites, Materials Today: Proceedings 5: 6018-6022.

13. Suresha S, Sridhara BK (2012) Friction characteristics of aluminium silicon carbide graphite hybrid composites, Materials and Design 34: 576-583.

14. Velmurugan C, Subramanian R, Thirugnanam S, Anandavel B (2012) Investigation of friction and wear behavior of hybrid aluminium composites, Industrial Lubrication and Tribology: 64(3): 152-163.

15. Kavimani V, Soorya Prakash K, Titus Thankachan (2019) Experimental investigations on wear and friction behaviour of SiC@r-GO reinforced $\mathrm{Mg}$ matrix composites produced through solvent-based powder metallurgy, Composites Part B 162: 508-521.

16. Faiz Ahmad, Jason Lo SH, Muhammad Aslam, Ahmad Haziq (2013) Tribology Behaviour of Alumina Particles Reinforced Aluminium Matrix Composites and Brake Disc Materials, Procedia Engineering, 68: 674-680. 
17. Alidokht SA, Abdollah-zadeh A, Assadi H (2013) Effect of applied load on the dry sliding wear behaviour and the subsurface deformation on hybrid metal matrix composite, Wear, 305: 291-298.

18. Umanath K, Palanikumar K, Selvamani ST (2013) Analysis of dry sliding wear behaviour of Al6061/SiC/A12O3 hybrid metal matrix composites, Composites Part B, 53: 159-168.

19. Kumar CR, Malarvannan RRR, JaiGanesh V (2020) Role of SiC on Mechanical, Tribological and Thermal Expansion Characteristics of $\mathrm{B}_{4} \mathrm{C} /$ Talc-Reinforced Al-6061 Hybrid Composite, Silicon, 12: 1491-1500.

20. Uthayakumar M, Aravindan S, Rajkumar K (2013) Wear performance of Al-SiC-B4C hybrid composites under dry sliding conditions, Materials and Design, 47: 456-464.

21. Ravinder Kumar, Suresh Dhiman (2013) A study of sliding wear behaviors of Al-7075 alloy and Al-7075 hybrid composite by response surface methodology analysis, Materials and Design, 50: 351-359.

22. Ravinderan E, Manisekar K, Rathika T, Narayanasamy P (2013), 'Tribological properties of powder metallurgy - Processed aluminium self-lubricating hybrid composites with $\mathrm{SiC}$ additions, Materials and Design, 45: 561-570.

23. Dey D, Bhowmik A, Biswas A (2020) Effect of SiC Content on Mechanical and Tribological Properties of Al2024-SiC Composites, Silicon. https://doi.org/10.1007/s12633020-00757-y

24. Ege Anil Diler, Rasim Ipek (2013) Main and interaction effects of matrix particle size, reinforcement particle size and volume fraction on wear characteristics of $\mathrm{Al}-\mathrm{SiCp}$ composites using central composite design, Composites Part B: Engineering, 50: 371-380.

25. Baradeswaran A, Elayaperumal A, Franklin Issac R (2013) A Statistical Analysis of Optimization of Wear Behaviour of $\mathrm{Al}-\mathrm{Al}_{2} \mathrm{O}_{3}$ Composites Using Taguchi Technique, Procedia Engineering, 64: 973-982. 
26. Suswagata Poria, Goutam Sutradhar, Prasanta Sahoo (2019) Design of Experiments Analysis of Abrasive Wear Behavior of Stir Cast Al-TiB2 Composites, Materials Today: Proceedings 18: 4253-4260.

27. John C Fradaric, Paul R Christu, Singh S Christopher Ezhil, Jacobjose J, Kumar T Ram (2017) Optimization on Wear Behavior of Al-12Si Alloy Reinforced with ZrC Nano Particle using Factorial Design, Asian Journal of Research in Social Sciences and Humanities, 7(3): $935-944$.

28. Chidozie Chukwuemeka Nwobi-Okoye, Chizoba Uzoma Uzochukwu (2020) RSM and ANN modeling for production of Al 6351/ egg shell reinforced composite: Multi objective optimization using genetic algorithm, Materials Today Communications, 22, 100674.

29. Chidozie Chukwuemek, Nwobi-Okoye, Basil Quent Ochieze, StanleyOkiy (2019) Multiobjective optimization and modeling of agehardening process using ANN, ANFIS and geneticalgorithm: Results from aluminum alloy A356/cow horn particulate composite, Journal of Materials Research and Technology, 8 (3): 3054-3075.

30. Sudarsana Rao H, Vaishali G Ghorpade, Mukherjee A (2006) A genetic algorithm based back propagation network for simulation of stress-strain response of ceramic-matrixcomposites, Computers \& Structures, 84 (5-6): 330-339.

31. Gangadhara Rao P, Gopala Krishna A, Vundavalli PR (2015) Parameter optimization of Al$\mathrm{SiC}$ metal matrix composites produced using powder-based process, 2015 International Conference on Robotics, Automation, Control and Embedded Systems (RACE), pp. 1-5.

32. Box GEP, Draper NR (1987). Empirical model building and response surfaces. John Wiley \& Sons, Inc.

33. Shang JS, Tadikamalla PR (1993). Output maximization of a CIM system: Simulation and statistical approach. International Journal of Production Research, 31:19-41. 
34. Cochran WG, Cox GM (1963) Experimental design. Asia Publishing, India

35. Josef Dick, Takashi Goda, Takehito Yoshiki (2019) Richardson extrapolation of polynomial lattice rules. SIAM Journal on Numerical Analysis, 57(1):44-69.

36. Montgomery DC (1976) Design and analysis of experiments. Wiley, New York

37. Holland JH (1975). Adaptation in Natural and Artificial Systems. The University of Michigan Press, Ann Arbor, MI.

38. Goldberg DE (1989). Genetic Algorithms in Search, Optimization, and Machine Learning. Addison-Wesley, Reading, MA.

39. Michalewicz Z (1996). Genetic Algorithms + Data Structures = Evolution Programs. Springer-Verlag, Berlin, Germany 